\title{
Article
}

\section{Serum MicroRNAs as Biomarkers of Sepsis and Resuscitation}

\author{
Lorena Oteiza $^{1}$, Antonio Ferruelo ${ }^{1,2}$, Nicolás Nín ${ }^{2,3}$, Mario Arenillas ${ }^{1,4}$, Marta de Paula ${ }^{1,2} \mathbb{D}$, Rachele Pandolfi $^{5}$, \\ Laura Moreno $^{2,6}{ }^{(D}$, Raquel Herrero ${ }^{1,2}\left(\mathbb{D}\right.$, Paloma González-Rodríguez ${ }^{1}$, Óscar Peñuelas ${ }^{1,2}(\mathbb{D}$, \\ Francisco Pérez-Vizcaíno ${ }^{2,6}$ and José A. Lorente $1,2,7, *$ (D)
}

1 Servicio de Medicina Intensiva y Grandes Quemados, Hospital Universitario de Getafe, 28095 Madrid, Spain; lorena.oteiza@salud.madrid.org (L.O.); antoniojose.ferruelo@salud.madrid.org (A.F.); veterimario@yahoo.es (M.A.); marta.paula@salud.madrid.org (M.d.P.); rherrero@salud.madrid.org (R.H.); Palomagonzalezrodriguez@iisgetafe.com (P.G.-R.); oscar.penuelasro@salud.madrid.org (Ó.P.)

2 CIBER de Enfermedades Respiratorias, Instituto de Salud Carlos III, 28029 Madrid, Spain; niconin@hotmail.com (N.N.); lmorenog@med.ucm.es (L.M.); fperez@med.ucm.es (F.P.-V.)

3 Hospital Español de Montevideo, Montevideo 11800, Uruguay

4 Facultad de Veterinaria, Universidad Complutense de Madrid, 28040 Madrid, Spain

5 Clínica Tambre, 28002 Madrid, Spain; pandolfi.rachele@gmail.com

6 Facultad de Medicina, Universidad Complutense de Madrid, 28040 Madrid, Spain

7 School of Medicine, Universidad Europea, 28670 Madrid, Spain

* Correspondence: joseangel.lorente@salud.madrid.org; Tel.: +34-649196626

check for updates

Citation: Oteiza, L.; Ferruelo, A.; Nín, N.; Arenillas, M.; de Paula, M.; Pandolfi, R.; Moreno, L.; Herrero, R.; González-Rodríguez, P.; Peñuelas, Ó.; et al. Serum MicroRNAs as Biomarkers of Sepsis and Resuscitation. Appl. Sci. 2021, 11, 11549. https://doi.org/10.3390/ app112311549

Academic Editor: Hans Peter Deigner

Received: 2 August 2021

Accepted: 23 November 2021

Published: 6 December 2021

Publisher's Note: MDPI stays neutral with regard to jurisdictional claims in published maps and institutional affiliations.

Copyright: (C) 2021 by the authors Licensee MDPI, Basel, Switzerland. This article is an open access article distributed under the terms and conditions of the Creative Commons Attribution (CC BY) license (https:// creativecommons.org/licenses/by/ $4.0 /)$.

\begin{abstract}
There is a lack of biomarkers of sepsis and the resuscitation status. Our objective was to prove that the serum expression of certain microribonucleic acids (miRNAs) is differentially regulated in sepsis and is sensitive to different resuscitation regimes. Anesthetized pigs (Sus scrofa domesticus) received no treatment $(n=15)$ or intravenous live $E$. coli $(n=24)$. The septic animals received $0.9 \%$ saline at $4 \mathrm{~mL} / \mathrm{kg} / \mathrm{h}(n=8)$ (low resuscitation group $(\mathrm{LoR})$ ) or $10-17 \mathrm{~mL} / \mathrm{kg} / \mathrm{h}$ (high resuscitation group (HiR)) ( $n=8$ each group). Blood samples were obtained at the end of the experiment for measurement of seven different miRNAs (RT-qPCR, Qiagen, Hilden, Germany). The serum expression of miR-146a-5p and miR-34a-5p increased significantly in the septic group, and miR-146a-5p was significantly lower in the HiR group than in the LoR group. The toll-like receptor signaling pathway involving 22 target proteins was significantly (adjusted $p=3.87 \times 10^{-4}$ ) regulated by these two microRNAs (KEGG). Highly significant $\left(p\right.$ value $\left.=2.22 \times 10^{-16}\right)$ protein-protein interactions (STRING) were revealed for these 22 hits. MiR-146a-5p and miR-34a-5p were identified as biomarkers of sepsis, and miRNA146a-5p seemed to be a biomarker of the intensity of the resuscitation.
\end{abstract}

Keywords: acute illness; animal model; biomarker; critical illness; bioinformatics; miRNA; precision medicine; profiling; resuscitation; metabolite target analysis; resuscitation; sepsis; systems biology

\section{Introduction}

Sepsis is defined as life-threatening organ dysfunction caused by a dysregulated host response to infection [1]. Mortality is in excess of $10 \%$ for mild cases of infection and organ dysfunction, but it reaches approximately $50 \%$ for cases with septic shock, a state of tissue hypoperfusion characterized by fluid-unresponsive hypotension requiring vasopressor agents accompanied by hyperlactatemia [1]. Early identification and treatment of sepsis is of paramount importance to prevent organ dysfunction and worsening acute lung injury [2]. The initial treatment of sepsis involves fluid resuscitation and the administration of antibiotics [1,2]. Nonetheless, there is a lack of biomarkers that can be used for the diagnosis and monitoring of the response to therapy (i.e., resuscitation) [3]. The biomarker sensitive to resuscitation that is widely used is the serum lactate concentration [4]. However, lactate formation during sepsis is not always related to tissue hypoxia as it is metabolized in the liver and in the kidney, and hyperlactatemia can be due to reduced clearance rather than to tissue hypoperfusion $[5,6]$. Thus, a biochemical marker of resuscitation would be of great clinical interest. 
Microribonucleic acids (miRNAs) are a particular type of non-coding RNA that is 19-25 nucleotides in length in its mature form and whose main function is gene regulation at the post-transcriptional level by blocking translation or inducing the degradation of messenger RNA $[7,8]$. miRNAs are ideal biomarkers, as they are stable in many body fluids (serum, plasma, urine, and bronchoalveolar lavage), can be readily measured by a reverse transcriptase quantitative polymerase chain reaction (RT-qPCR), and have already been shown to be sensitive and specific biomarkers for the diagnosis and response to therapy of many disease conditions [8]. In this line, miRNAs have been shown to play important roles as biomarkers of acute lung injury, one of the main organ dysfunctions in sepsis, as we have recently reviewed [9-11].

Some studies on the role of miRNAs as biomarkers of sepsis, both in small animal models and in patients, have been conducted [12]. In the present study, using a large animal model of sepsis, we hypothesized that the serum expression of candidate miRNAs changes under conditions of sepsis and is sensitive to resuscitation.

\section{Materials and Methods}

\subsection{Animal Preparation and Monitoring}

We used male pigs (Sus scrofa domesticus) aged 2.5-3 months old and weighing between 25 and $30 \mathrm{~kg}$ (see Supplementary Materials). We studied biological samples from control (non-septic, $n=15$ ) and septic pigs $(n=24)$. After overnight fasting, the pigs were sedated with ketamine $(15 \mathrm{mg} / \mathrm{kg})$ and midazolam $(0.5 \mathrm{mg} / \mathrm{kg})$ intramuscularly. An ear vein was cannulated for the maintenance of sedation, analgesia, and muscle paralysis with propofol (0.1-0.3 mg/ $\mathrm{kg} / \mathrm{min})$, fentanyl $(5 \mu \mathrm{gr} / \mathrm{kg} / \mathrm{h})$ and atracurium $(0.1 \mathrm{mg} / \mathrm{kg} / \mathrm{h})$. Once sedated, a tracheostomy was performed after administering $2 \%$ lidocaine $(0.2 \mathrm{~mL} / \mathrm{kg})$ subcutaneously, and an endotracheal tube was introduced and connected to a volumetric ventilator (Servo 900C; Siemens Elema, solna, Sweden) with the following settings: respiratory rate of 20 breaths per min, tidal volume of $15 \mathrm{~mL} / \mathrm{kg}$, fraction of inspired oxygen of 0.5 , and positive end-expiratory pressure of $5 \mathrm{~cm} \mathrm{H}_{2} \mathrm{O}$. The left jugular vein was cannulated for the insertion of a pulmonary arterial catheter and for fluid administration. The right carotid artery was cannulated for the measurement of blood pressures and blood sampling. A urinary catheter was introduced in the urinary bladder through a small suprapubic incision. See the Supplementary Materials for further details on the animal preparation and blood sampling.

\subsection{Protocol and Measurements}

After monitoring, the animals received $0.9 \%$ sodium chloride at $4 \mathrm{~mL} / \mathrm{kg} / \mathrm{h}$ and were randomly allocated to the different groups. After a 30-min resting period, sepsis was induced at $t=0 \mathrm{~h}$ by the administration of an intravenous infusion of live Escherichia coli $\left(2 \times 10^{8} \mathrm{CFU} / \mathrm{mL} \mathrm{mL} / \mathrm{kg}\right.$, serotype O26:H11, isolated from blood cultures from a patient with septic shock) over $30 \mathrm{~min}$. The non-septic animals $(n=15)$ received an equivalent amount of saline over $30 \mathrm{~min}$. From $t=0 \mathrm{~h}$ and during the remaining $5 \mathrm{~h}$, the non-septic animals received $0.9 \%$ sodium chloride at $4 \mathrm{~mL} / \mathrm{kg} / \mathrm{h}$ throughout the experiment. The septic animals, depending on the resuscitation group, received $0.9 \%$ sodium chloride at 4,10 , or $17 \mathrm{~mL} / \mathrm{kg} / \mathrm{h}(n=8$ for each group) starting at $t=0$. This septic challenge used induced the biochemical, hematological, and hemodynamic changes characteristic of human sepsis.

At $t=0 \mathrm{~h}$ (right before the infusion of E. coli or the placebo) and then hourly, we measured the different hemodynamic parameters. The pressures were measured and displayed (Hewlett Packard monitor, Madrid, Spain). We registered the mean systemic arterial pressure (MAP), mean pulmonary artery pressure (MPAP), right atrial pressure (RAP), and pulmonary artery occlusion pressure (PAOP). Cardiac output (QTOT) was measured by the thermodilution technique (CO computer; Abbott Labs: Chicago, IL 60064, USA). Systemic (SVR) and pulmonary (PVR) vascular resistances were calculated (MAP-RAP/QTOT and PAP-MPAP/QTOT, respectively) and expressed as arbitrary units. 
Blood samples were obtained at $t=0 \mathrm{~h}, t=1 \mathrm{~h}, t=3 \mathrm{~h}$, and $t=5 \mathrm{~h}$ for measurement of the creatinine and arterial lactate concentrations (Hitachi 911; Boehringer, Mannheim, Germany) and arterial blood gases (ABL 500; Radiometer, Copenhagen, Denmark). A serum sample obtained at the end of the experiment was frozen and stored at $-80^{\circ}$ for later measurement of the cytokines and miRNAs.

The experiment was terminated at $t=5 \mathrm{~h}$ or if severe hypotension (MAP $<20 \mathrm{~mm} \mathrm{Hg}$ ) ensued. At that point, the animal was sacrificed by an intravenous injection of thiopental (15 mg/kg intravenously). After the animal's death, the left kidney fossa was accessed through a left-sided lumbotomy, and samples of the renal cortex and the renal medulla were cut and stored at $-80^{\circ}$ until further analysis.

We followed the current European and national legislation on the use of laboratory animals (Principles of Laboratory Animal Care, 2010/63/UE and Real Decreto 53/2013 BOE-08/02). This study was approved by the institutional and the local government animal research ethics committees.

\subsection{Blood Sample Analysis}

The cytokines were measured by ELISA (DuoSet kits (R\&D Systems, Minneapolis, MN, USA) (see Supplementary Materials). The miRNAs were measured by RT-qPCR (Qiagen, Hilden, Germany). See the Supplementary Materials for details on miRNA isolation from the serum, miRNA cDNA preparation, and RT-Qpcr.

\subsection{Enrichment and Functional Analysis}

Genes targeted by the miRNAs of interest were identified using miRNet 2.0 (www. mirnet.ca, last accessed on 20 July 2021). Pathways involved in a given set of proteins were identified by the KEGG Pathway Database (www.genome.jp/kegg/, last accessed on 25 July 2021). Other tools such as the Reactome Pathway Database (reactome.org, last accessed on 25 July 2021) and Gene Ontology (geneontology.org, last accessed on 25 July 2021) were also used for the identification of relevant biological pathways at the protein level.

Protein-protein interaction (PPI) and functional enrichment analysis were studied using the Search Tool for the Retrieval of Interacting Genes/Proteins (STRING) [13]. The interactions studied included direct (physical) and indirect (functional) associations. An interaction score of 0.9 (meaning high confidence with fewer false positives interactions) was used. Of the different types of interaction (fusion, neighborhood, cooccurrence, experimental, textmining, database, and coexpression), only experimental evidence and database evidence were considered. Clusters with a minimum of 5 proteins per cluster were generated.

\subsection{Statistical Analysis}

Results for non-normally distributed continuous variables are presented as medians and 25th and 75th percentiles. The statistical differences in the intensity of resuscitation in both the septic groups and the control group were evaluated by the Kruskal-Wallis test, post hoc analysis with the Mann-Whitney $U$ test, and correction for multiple comparisons with Holm's method. Survival curves were also analyzed by the Kaplan-Meier method and logrank Mantel-Cox test. A two-tailed significance level of 0.05 was used for all statistical tests. All statistical analyses used SPSS software (version 20.0).

\section{Results}

\subsection{Description of the Animal Model: Effects of Sepsis and Resuscitation}

Sepsis induced a state of increased heart rate, systemic hypotension, decreased RAP, increased MPAP, decreased SVR, and increased PVR (Table S1). Sepsis was also associated with increased serum creatinine and arterial blood lactate concentrations and a decreased arterial $\mathrm{pH}$ and $\mathrm{PaO} 2$ (Table S2). 
Resuscitation was associated with attenuation (that did not reach statistical significance) of the sepsis-induced changes in MAP, RAP, and (reaching statistical significance) in PVR (Table S1). Additionally, the sepsis-induced changes in serum creatinine and arterial blood lactate concentrations as well as arterial $\mathrm{pH}$ and $\mathrm{PaO} 2$ tended to be milder in the resuscitation groups (Table S2).

During the observation period, none of the animals in the control group and 9 animals in the septic group died before $5 \mathrm{~h}: 5$ pigs in the $4 \mathrm{~mL} / \mathrm{kg} / \mathrm{h}$ resuscitation group ( 1 before $t=2 \mathrm{~h}$ and 4 before $t=3 \mathrm{~h}$ ); 3 pigs in the $10 \mathrm{~mL} / \mathrm{kg} / \mathrm{h}$ resuscitation group (before $t=4 \mathrm{~h}$ ); and 1 pig in the $17 \mathrm{~mL} / \mathrm{kg} / \mathrm{h}$ resuscitation group (before $t=5 \mathrm{~h})(p<0.001$, logrank Mantel-Cox test) (Figure S1). During the experiments, the animals with less severe clinical abnormalities tended to survive longer. Thus, this selection bias and the reduced sample size overtime should be considered when interpreting the hemodynamic and biochemical changes observed in the animals.

\subsection{Changes in Cytokine and miRNA Expression}

Comparisons of all hemodynamic and biochemical parameters between the sepsis group resuscitated with $10 \mathrm{~mL} / \mathrm{kg} / \mathrm{h}$ and the sepsis group resuscitated with $17 \mathrm{~mL} / \mathrm{kg} / \mathrm{h}$ were not significantly different $(p>0.1$ for all the hemodynamic and biochemical comparisons). Therefore, these two sepsis groups (resuscitated with $10 \mathrm{~mL} / \mathrm{kg} / \mathrm{h}$ and resuscitated with $17 \mathrm{~mL} / \mathrm{kg} / \mathrm{h}$ ) were combined (high resuscitation (HiR)) for comparison with the sepsis group resuscitated with $4 \mathrm{~mL} / \mathrm{kg} / \mathrm{h}$ (low resuscitation (LoR)) and the control (non-septic) groups. The samples available for analysis for the control (non-septic), LoR septic, and HiR septic groups were between 5 and 6 , between 3 and 4, and between 3 and 10, respectively (Table S3).

The serum concentrations of IL- $1 \beta, \mathrm{TNF} \alpha$, IL-6, and IL- $1 \beta$ in the renal medulla were higher in the septic group. The IL-1 $\beta$ concentrations in the renal cortex trended higher in the septic group (not significant) (Table S4). The concentration of all cytokines studied tended to decrease in the sepsis HiR group compared with the sepsis LoR group, the difference reaching statistical significance for the TNF- $\alpha$ serum concentration (Table S4).

The serum expression of miRNA34a-5p and miR-146a-5p increased significantly in the septic groups ( $p=0.010$ and $p=0.016$, respectively, for the overall between group differences) (Table S5). The post hoc comparison between the LoR and HiR groups (effect of resuscitation) reached statistical significance only for miRNA146a-5p (Table S5). miR-155-5p tended to increase after the septic challenge and decrease with HiR as compared with LoR, with changes that did not reach statistical significance (Figure 1, Tables S5 and S6).

\subsection{Enrichment and Functional Analysis}

There were 1386 genes identified as regulated by both miRNAs (MiRNet). Enrichment analysis (KEGG) identified the Toll-like receptor signaling pathway as being significantly regulated (the third in order of significance), with 22 hits (adjusted $p$ value $=3.87 \times 10^{-4}$ ). Toxoplasmosis was the most highly significant pathway regulated by the miRNAs of interest with 24 hits (adjusted $p$ value $=3.77 \times 10^{-5}$ ), of which 10 were common to the Toll-like receptor signaling pathway (Tables S7 and S8) (Figures 2 and S2). 

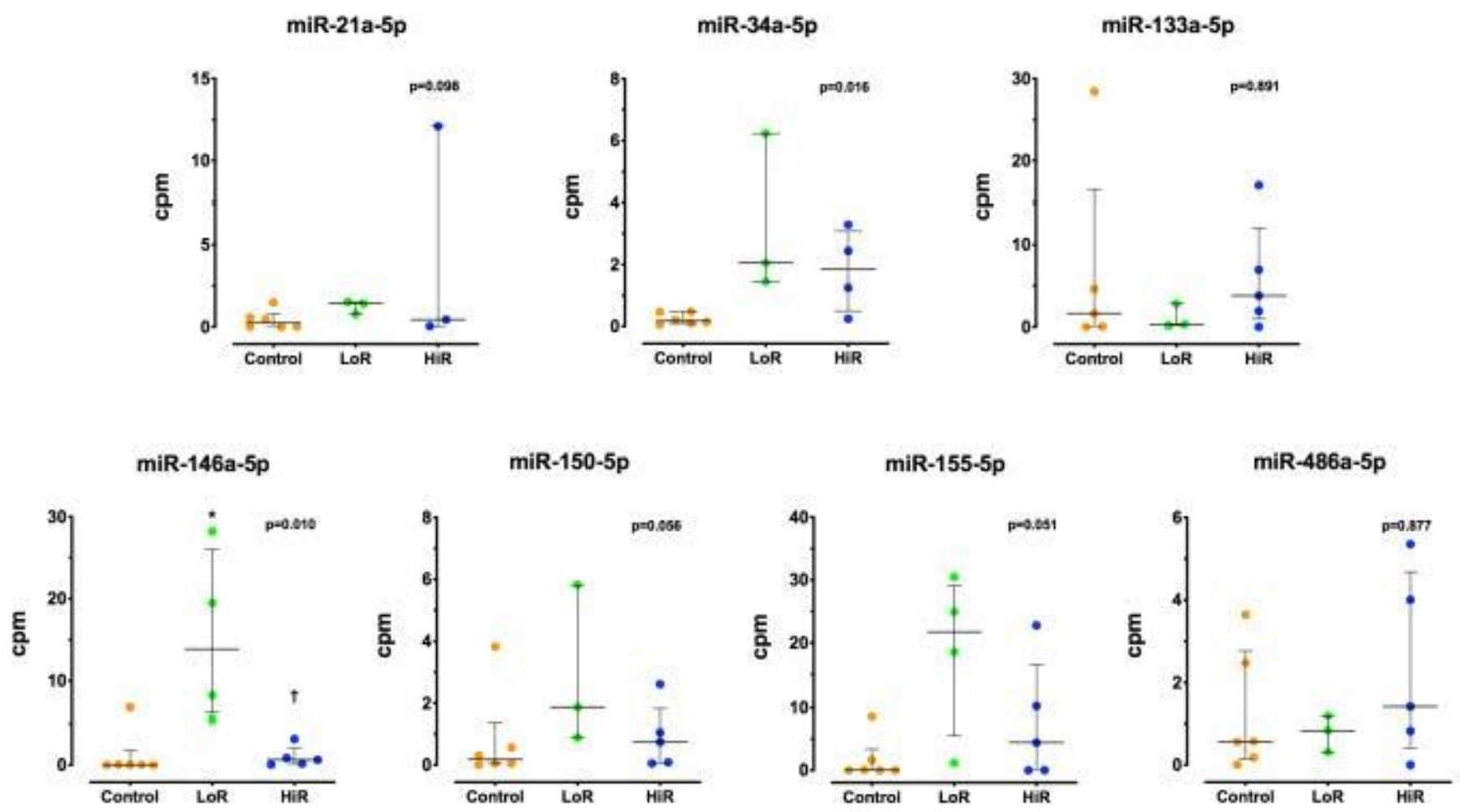

Figure 1. miRNA serum expression in control and septic animals receiving low (LoR) or high (HiR) fluid resuscitation. Bars indicate median, percentile 25 th and percentile 75 th. The $\mathrm{p}$ values indicate the statistical significance between the group differences (Kruskal-Wallis test). ${ }^{*} p<0.05$ versus control group. $\dagger p<0.05$ versus LoR group (Mann-Whitney test with Holm's correction).
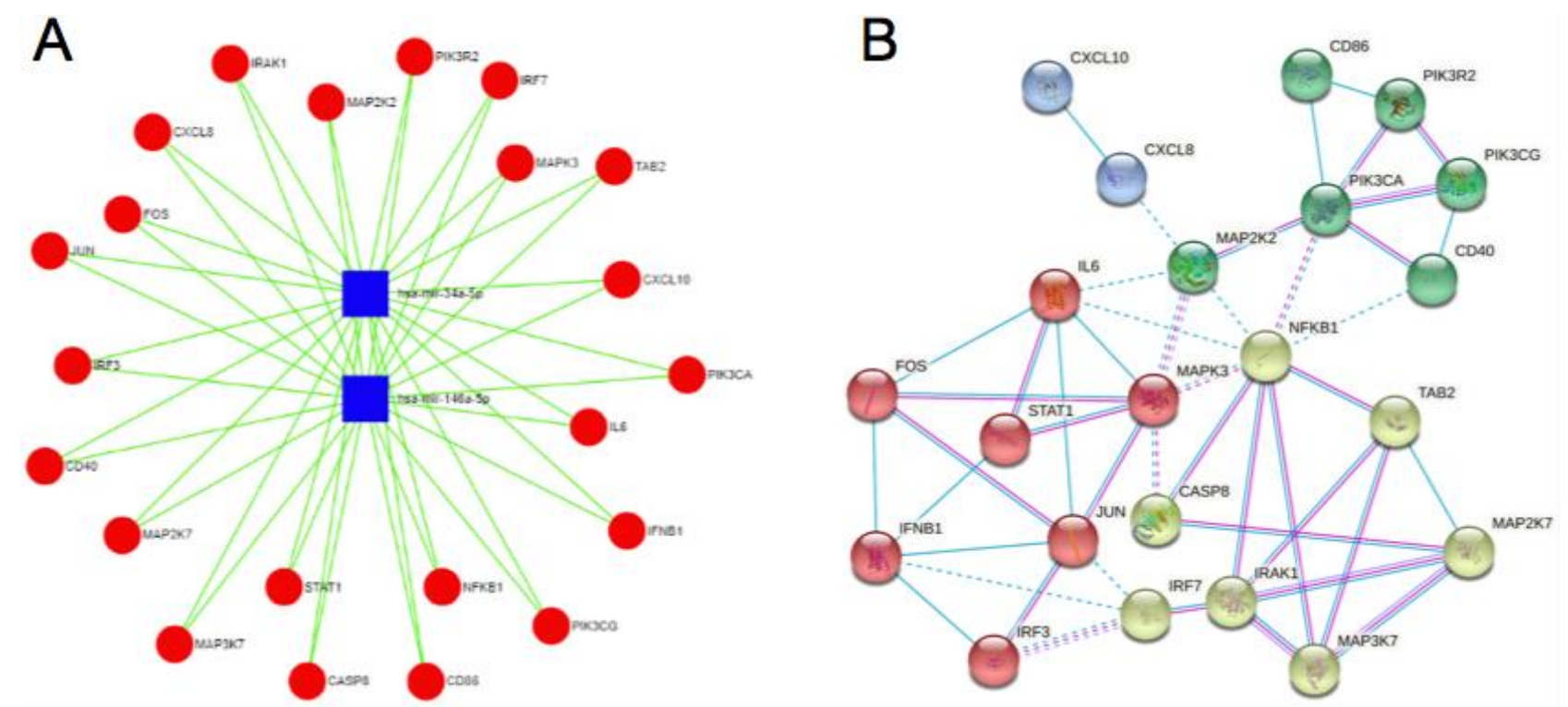

Figure 2. (A) Genes targeted by miR-146a-5p and miR-34a-5p participating in the Toll-like receptor signaling pathway (KEGG). (B) Protein-protein interaction (STRING) of the 22 hits (STRING, confidence 0.9, in 4 clusters). Purple line, experimental evidence. Light blue line, database evidence. Dotted lines, interactions appearing only after clustering. Proteins are involved in multiple immune regulation and cytokine signaling pathways.

Proteins of the Toll-like receptor signaling pathway regulated by the miRNAs of interest (Table S8) were involved (KEGG) as the five more significant pathways in the Toll-like receptor signaling pathway, Kaposi's sarcoma-associated herpesvirus infection, hepatitis B, influenza A, and TNF signaling pathway(Table S9). Using Reactome, the top 
five were cytokine signaling in the immune system, interleukin-6 signaling, hemostasis, downstream signaling events of B cell receptors (BCRs), and PIP3 activating AKT signaling (Table S10). Finally, using Gene Ontology biological processes, the top five pathways related to the 22 Toll-like receptor signaling pathway proteins were positive regulation of immune system processes, the response to cytokine, the cytokine-mediated signaling pathway, regulation of immune response, and positive regulation of signal transduction (Table S11) (all with adjusted $p<0.001$ ).

Similarly, proteins of the toxoplasmosis pathway regulated by the miRNAs of interest (Table S8) were involved, as the five most significant pathways (with adjusted $p<0.001$ ) were in toxoplasmosis, the Toll-like receptor signaling pathway, small-cell lung cancer, the TNF signaling pathway, and pathways in cancer (KEGG) Table S12). Using Reactome the only pathway regulated with adjusted $p<0.001$ was hemostasis (Table S13). Finally, using Gene Ontology biological processes, the top five pathways related to the 24 toxoplasmosis pathway proteins (with adjusted $p<0.001$ ) were intracellular signal transduction, regulation of catalytic activity, cellular response to chemical stimulus, cellular response to organic substances, and response to organic substances (Table S14).

We analyzed the PPIs for the 22 proteins of the Toll-like receptor signaling pathway (STRING, confidence of 0.9 in 4 clusters). The PPIs were highly significant (PPI enrichment $p$ value: $2.22 \times 10^{-16}$ ) (Figure 2). The PPIs for the 24 proteins of the toxoplasmosis pathway were also analyzed (PPI enrichment $p$ value $<1.0 \times 10^{-16}$ ) (Table S8 and Figure S2).

\section{Discussion}

The main findings of our study in a large animal model of sepsis were that (1) the serum expression of miR-146a-5p and miR-34a-5p was upregulated after a septic challenge, and (2) miR-146a-5p expression was modulated by the intensity of the fluid resuscitation. These findings are of paramount importance for the discovery of biomarkers of sepsis and resuscitation, as well as the identification of novel therapeutic targets.

Our animal model features human sepsis, including systemic vasodilation and pulmonary vasoconstriction, hyperlactatemic acidosis, marked pro-inflammatory response, and substantial mortality. The concentrations of IL- $1 \beta$, TNF- $\alpha$, and IL- 6 in the serum, as well as the concentration of IL- $1 \beta$ in the renal tissue (medulla and renal cortex), increased after the septic challenge, demonstrating an inflammatory response both systemically and at the tissue level as part of the immune response to sepsis. Fluid resuscitation attenuated some of the hemodynamic changes (e.g., the decrease in MAP and RAP), the hyperlactatemic acidosis, and the magnitude of the inflammatory response (i.e., increased TNF- $\alpha$ and, nonsignificantly, IL- 6 serum concentration and IL-1 $\beta$ serum and kidney tissue concentrations).

Recent studies have investigated the role of different miRNAs as biomarkers of sepsis in small animal models and in human sepsis [12,14]. The novelty of the present investigation is the study of the expression of different miRNAs in a large animal model of sepsis and their response to fluid resuscitation. In this context, we found that sepsis was associated with increased serum expression of miR-34a-5p and miR-146a-5p. In addition, we found that the serum expression of miR-146a-5p was significantly lower in the HiR group compared with the LoR group. The expression of miR-155-5p followed the same pattern, albeit with differences that did not reach statistical significance $(p=0.051)$.

The miRNAs measured in the present investigation were chosen based in their known role in the inflammatory response, a key element in the pathobiology of sepsis (discussed in detail in the Supplementary Materials) [15-22].

Our findings of increased levels of miR-34a-5p in sepsis are in line with the results of other in vitro studies [16,17] and with the results of sepsis models in mice treated with cecal ligation and puncture [23] and rats given LPS [24].

We found significant upregulation of miR-146a-5p in sepsis. These findings confirm and expand previous results showing increased expression of this miRNA in blood from mice undergoing cecal ligation and puncture $[25,26]$ and in muscle tissue from pigs 
treated with LPS [27]. However, those findings seem to contradict the reported changes in miR-146a-5p expression in patients with sepsis, in whom miR-146a-5p was either downregulated $[28,29]$ or unchanged $[30]$ compared with patients with systemic inflammatory response (SIRS) and healthy controls. These discrepancies could be explained by differences in the sampling time, which in the experimental model occurred very early after the septic challenge. Notwithstanding these apparently discrepant results, our findings confirmed the role of miR-146a-5p as a biomarker of sepsis in a large animal model of sepsis. In addition, we provided for the first time evidence that the expression of miR-146a-5p was sensitive to the dose of fluid resuscitation.

In general, despite the significant changes observed in the expression of miR-34a-5p and miR-146a-5p, we could not conclude the role of the other miRNAs measured herein as biomarkers of sepsis and resuscitation in our model, as some observed trends did not reach statistical significance. Changes in the expression of miRNA150-5p $(p=0.056)$ and miRNA155-5p $(p=0.051)$ allowed for the speculation that these miRNAs could also be useful as biomarkers of sepsis, in line with previous results [31], and that in the case of miRNA155-5p, a role as biomarker of resuscitation is worth pursuing in future studies.

Given their role in the immune response, our findings of increased serum expression of miR-146a-5p and miR-34a-5p were expected. However, these findings have not been previously reported in a clinically relevant large animal model of sepsis nor has the association with resuscitation been described. The role of the miRNAs measured herein in other in vitro models, as well as other biomarkers of sepsis, is discussed in further detail in the Supplementary Materials [32-53].

Changes in miRNA expression are expected to occur in sepsis. Conditions that take place in sepsis, such as inflammation and hypoxia, are known to regulate miRNA expression, which is under the control of transcription factors that play roles in the inflammatory response [54].

Our findings on the relationship between the serum expression of certain miRNAs and the intensity of the resuscitation is of great clinical interest. Currently, the serum lactate concentration is widely used for the diagnosis of tissue hypoperfusion and to monitor the response to resuscitation [1,2]. However, elevations of serum lactate could be due to reduced clearance in the context of sepsis and liver dysfunction and thus not always reflect tissue hypoperfusion [4-6]. The serial measurement of several hemodynamic variables can monitor the achievement of predefined hemodynamic objectives during resuscitation. However, a biochemical biomarker of resuscitation would be a noninvasive biomarker of resuscitation complementary to the currently available hemodynamic measurements and could provide information about cellular changes sensitive to hypoperfusion.

\subsection{Enrichment and Functional Analysis of miR-34a-5p and miRNA146a-5p}

Using microRNA target prediction tools, we found that 1386 genes were regulated by the two miRNAs of interest. These genes were involved in many different biological pathways. Of note, one of the most significantly regulated pathways was the Toll-like receptor signaling pathway, with 22 proteins of this pathway represented in our network. The PPIs of these proteins were highly significant (PPI enrichment $p$ value: $2.22 \times 10^{-16}$ ), indicating that our network had significantly more interactions than would be expected for a random set of proteins of a similar size drawn from the genome. Such an enrichment indicates that the proteins were at least partially biologically connected as a group. Enrichment analysis using different tools indicated that these proteins were involved in processes critical to the pathobiology of sepsis, such as such as the TNF signaling pathway, cytokine signaling in the immune system, interleukin-6 signaling, downstream signaling events of $\mathrm{B}$ cell receptors, AKT signaling, the response to cytokine, the cytokine-mediated signaling pathway, and regulation of immune response. Our findings support the hypothesis that these biomarkers, sensitive to the diagnosis of sepsis and to the quality of resuscitation, could also be therapeutic targets and that functional interference of these miRNAs could cause significant physiological effects in pathways known to be critical in sepsis. 


\subsection{Limitations}

This study has several limitations. First, the sample size probably explained why some of the differences did not reach statistical significance. However, despite this limitation, we were able to prove significant differences between the septic and non-septic groups and between the different resuscitation regimes. The nonsignificant trends observed in some comparisons could have become significant had the sample size been larger. Pending further confirmation, our results provide the proof of concept that miRNAs could be useful biomarkers in a large animal model to be tested later in patients and that miRNAs could also be biomarkers of resuscitation. Second, the comparison groups were sepsis and healthy controls. Thus, we could not conclude based on our results that the biomarkers identified were specific for sepsis, as they could also be increased in other conditions associated with a systemic inflammatory response of a non-infectious origin. Finally, the clinical significance of our model is limited, as some therapeutic interventions commonly used in patients, such as the administration of antibiotics, were not planned in the present animal model. In addition, the regimens of fluid resuscitation studied herein were not titrated to a specific physiological endpoint, whereas in clinical practice, fluid resuscitation is aimed at the achievement of specific physiological goals. Another aspect that limits the clinical relevance of the model is the 5-h follow-up period, which may not allow for the development of the full physiological response to a septic stimulus as is usually seen in patients. In addition, the massive septic challenge may not necessarily translate into the nature of the infectious insults that patients generally suffer. However, we believe that our model, reproducing the most important hemodynamic and biochemical characteristics of human sepsis, is useful for better understanding the pathophysiology of sepsis and the response (e.g., of miRNA expression) to sepsis. We portend that the results derived from this model are, at least as a proof of concept, valid to propose new biomarkers that can be used for the discovery of biological pathways relevant to the pathobiology of disease and for the discovery of novel therapeutic targets.

\section{Conclusions}

In summary, the present study provides new insights into the role of miRNAs as biomarkers of sepsis and resuscitation. We report, for the first time, changes in the serum expression of several miRNAs in a large animal model and their relationship with the intensity of fluid resuscitation. More studies comparing sepsis with non-infectious SIRS are needed to confirm our findings.

Supplementary Materials: The following are available online at https:/ /www.mdpi.com/article/ 10.3390/app112311549/s1. Table S1: Effect of sepsis and resuscitation on hemodynamic variables. Table S2: Effect of sepsis and resuscitation on biochemical variables. Table S3: Sample size for cytokine and miRNA determinations in the different groups. Table S4: Effect of sepsis and resuscitation on cytokine concentration. Table S5: Effect of sepsis and resuscitation on serum miRNA expression. Table S6: miRNAs differentially expressed in control versus septic animals: miRNA146-5p and miRNA34a-5p. Table S7: Pathways targeted by both miRNA34a-5p and miR-146a-5p (KEGG enrichment analysis) (adjusted $p<0.01$ ). Table S8: Proteins in our network participating in the Toll-like receptor and in the toxoplasmosis pathways. In red are proteins common to both pathways. Table S9: Enrichment analysis (KEGG) of proteins in the Toll-like receptor pathway (STRING) (adjusted $p$ value $<0.0000001$ ). Table S10: Enrichment analysis (Gene Ontology biological process) of proteins in the Toll-like receptor pathway (STRING) (adjusted $p$ value $<0.0000001$ ). Table S11: Enrichment analysis (reactome) of proteins in the Toll-like receptor pathway (STRING) (adjusted $p$ value $<0.001$ ). Table S12: Enrichment analysis (KEGG) of proteins in the toxoplasmosis pathway (STRING) (adjusted $p$ value $<0.0000001$ ). Table S13: Enrichment analysis (Gene Ontology biological process) of proteins in the toxoplasmosis pathway (STRING) (adjusted $p$ value $<0.0000001$ ). Table S14: Enrichment analysis (reactome) of proteins in the toxoplasmosis pathway (STRING) (adjusted $p$ value $<0.001$ ). Figure S1: Mortality of the different experimental groups (control, $n=15$; sepsis $4 \mathrm{~mL} / \mathrm{kg} / \mathrm{h}, n=8$; sepsis $10 \mathrm{~mL} / \mathrm{kg} / \mathrm{h}$, sepsis $17 \mathrm{~mL} / \mathrm{kg} / \mathrm{h}$ ). Figure S2: (A) Genes targeted by both miRNAs of interest (miRNA146a-5p and miRNA34a-5p) (mirNet), where 1386 genes were identified as regulated by 
both miRNAs. (B) Toxoplasmosis as the most highly significant pathway regulated by the miRNAs of interest (KEGG enrichment analysis) with 24 hits (adjusted $p$ value $=3.77 \times 10^{-5}$ ), of which 10 were common with the Toll-like receptor signaling pathway. (C) Protein-protein interaction of the 24 proteins (STRING, confidence 0.9 , in 4 clusters). PPI enrichment $p$ value $=1.0 \times 10^{-16}$. Purple line $=$ experimental evidence; light blue line $=$ database evidence; dotted lines $=$ interactions appearing only after clustering.

Author Contributions: Conceptualization, L.O., A.F., N.N., R.H. and J.A.L.; methodology, A.F., R.H., R.P., M.A., M.d.P., L.M. and F.P.-V.; software, A.F., R.P. and P.G.-R.; validation, R.H., Ó.P., F.P.-V. and J.A.L.; formal analysis, N.N., L.M., R.H. and J.A.L.; investigation, L.O., A.F., N.N., M.A., F.P.-V. and J.A.L.; resources, F.P.-V. and J.A.L. All authors have read and agreed to the published version of the manuscript.

Funding: The APC were waived by the editorial office.

Institutional Review Board Statement: The Institutional Review Board of Hospital Universitario de Getafe, approved on 24 September 2015 with the protocol number PI15/1942.

Informed Consent Statement: Not applicable.

Data Availability Statement: Original data are available upon request.

Acknowledgments: Not applicable.

Conflicts of Interest: The authors declare no conflict of interest.

\section{References}

1. Singer, M.; Deutschman, C.S.; Seymour, C.W.; Shankar-Hari, M.; Annane, D.; Bauer, M.; Bellomo, R.; Bernard, G.R.; Chiche, J.D.; Coopersmith, C.M. The Third International Consensus Definitions for Sepsis and Septic Shock (Sepsis-3). JAMA 2016, 315, 801-810. [CrossRef]

2. Sakr, Y.; Jaschinski, U.; Wittebole, X.; Szakmany, T.; Lipman, J.; Namendys-Silva, S.A.; Martin-Loeches, I.; Leone, M.; Lupu, M.N.; Vincent, J.L. ICON Investigators. Sepsis in Intensive Care Unit Patients: Worldwide Data from the Intensive Care over Nations Audit. Open Forum Infect. Dis. 2018, 5, ofy313. [CrossRef]

3. Izquierdo-Garcia, J.L.; Nin, N.; Cardinal-Fernandez, P.; Rojas, Y.; de Paula, M.; Granados, R.; Martínez-Caro, L.; Ruíz-Cabello, J.; Lorente, J.A. Identification of novel metabolomic biomarkers in an experimental model of septic acute kidney injury. Am. J. Physiol. Renal Physiol. 2019, 316, F54-F62. [CrossRef]

4. Suetrong, B.; Walley, K.R. Lactic Acidosis in Sepsis: It's Not All Anaerobic: Implications for Diagnosis and Management. Chest 2016, 149, 252-261. [CrossRef] [PubMed]

5. Puskarich, M.A.; Trzeciak, S.; Shapiro, N.I.; Albers, A.B.; Heffner, A.C.; Kline, J.A.; Jones, A.E. Whole Blood Lactate Kinetics in Patients Undergoing Quantitative Resuscitation for Severe Sepsis and Septic Shock. Chest 2013, 143, 1548-1553. [CrossRef]

6. Rimachi, R.; De Carvahlo, F.B.; Orellano-Jimenez, C.; Cotton, F.; Vincent, J.L.; De Backer, D. Lactate/pyruvate ratio as a marker of tissue hypoxia in circulatory and septic shock. Anaesth Intensive Care 2012, 40, 427-432. [CrossRef]

7. O'Brien, J.; Hayder, H.; Zayed, Y.; Peng, C. Overview of MicroRNA Biogenesis, Mechanisms of Actions, and Circulation. Front. Endocrinol. (Lausanne) 2018, 9, 402. [CrossRef] [PubMed]

8. Lu, J.; Getz, G.; Miska, E.A.; Alvarez-Saavedra, E.; Lamb, J.; Peck, D.; Sweet-Cordero, A.; Ebert, B.L.; Mak, R.H.; Ferrando, A.A. MicroRNA expression profiles classify human cancers. Nature 2005, 435, 834-838. [CrossRef]

9. García-Laorden, M.I.; Lorente, J.A.; Flores, C.; Slutsky, A.S.; Villar, J. Biomarkers for the acute respiratory distress syndrome: How to make the diagnosis more precise. Ann. Transl. Med. 2017, 5, 283. [CrossRef] [PubMed]

10. Cardinal-Fernández, P.; Ferruelo, A.; Esteban, A.; Lorente, J.A. Characteristics of microRNAs and their potential relevance for the diagnosis and therapy of the acute respiratory distress syndrome: From bench to bedside. Transl. Res. 2016, 169, 102-111. [CrossRef]

11. Ferruelo, A.; Peñuelas, Ó.; Lorente, J.A. MicroRNAs as biomarkers of acute lung injury. Ann. Transl. Med. 2018, 6, 34. [CrossRef] [PubMed]

12. Benz, F.; Roy, S.; Trautwein, C.; Roderburg, C.; Luedde, T. Review: Circulating MicroRNAs as Biomarkers for Sepsis. Int. J. Mol. Sci. 2016, 17, 78. [CrossRef] [PubMed]

13. Szklarczyk, D.; Gable, A.L.; Lyon, D.; Junge, A.; Wyder, S.; Huerta-Cepas, J.; Simonovic, M.; Doncheva, N.T.; Morris, J.; Bork, P.; et al. STRING v11: Protein-protein association networks with increased coverage, supporting functional discovery in genome-wide experimental datasets. Nucleic Acids Res. 2019, 47, D607-D613. [CrossRef] [PubMed]

14. Wu, X.; Yang, J.; Yu, L.; Long, D. Plasma miRNA-223 correlates with risk, inflammatory markers as well as prognosis in sepsis patients. Medicine 2018, 97, e11352. [CrossRef] [PubMed] 
15. Xue, X.; Qiu, Y.; Yang, H.L. Immunoregulatory Role of MicroRNA-21 in Macrophages in Response to Bacillus Calmette-Guerin Infection Involves Modulation of the TLoR4/MyD88 Signaling Pathway. Cell Physiol. Biochem. 2017, 42, 91-102. [CrossRef] [PubMed]

16. Hart, M.; Walch-Rückheim, B.; Friedmann, K.S.; Rheinheimer, S.; Tänzer, T.; Glombitza, B.; Sester, M.; Lenhof, H.P.; Hoth, M.; Schwarz, E.C. MiR-34a: A new player in the regulation of T cell function by modulation of NF-kB signaling. Cell Death Dis. 2019, 10, 46. [CrossRef] [PubMed]

17. Ge, Y.; Huang, M.; Ma, Y.F. The effects of microRNA-34a regulating Notch-1/NF-kB signaling pathway on lipopolysaccharideinduced human umbilical vein endothelial cells. World J. Emerg. Med. 2017, 8, 292-296. [CrossRef] [PubMed]

18. Castaldi, A.; Zaglia, T.; Di Mauro, V.; Carullo, P.; Viggiani, G.; Borile, G.; Di Stefano, B.; Schiattarella, G.G.; Gualazzi, M.G.; Elia, L. MicroRNA-133 modulates the $\beta 1$-adrenergic receptor transduction cascade. Circ. Res. 2014, 115, 273-283. [CrossRef] [PubMed]

19. Taganov, K.D.; Boldin, M.P.; Chang, K.J.; Baltimore, D. NF-kappaB-dependent induction of microRNA miR-146, an inhibitor targeted to signaling proteins of innate immune responses. Proc. Natl. Acad. Sci. USA 2006, 103, 12481-12486. [CrossRef] [PubMed]

20. Vasilatou, D.; Papageorgiou, S.; Pappa, V.; Papageorgiou, E.; Dervenoulas, J. The role of microRNAs in normal and malignant hematopoiesis. Eur. J. Haematol. 2010, 84, 1-16. [CrossRef]

21. Schulte, L.N.; Westermann, A.J.; Vogel, J. Differential activation and functional specialization of miR-146 and miR-155 in innate immune sensing. Nucleic Acids Res. 2013, 41, 542-553. [CrossRef] [PubMed]

22. Li, J.; Zhou, Q.; Liang, Y.; Pan, W.; Bei, Y.; Zhang, Y.; Wang, J.; Jiao, Z. miR-486 inhibits PM2.5-induced apoptosis and oxidative stress in human lung alveolar epithelial A549 cells. Ann. Transl. Med. 2018, 6, 209. [CrossRef] [PubMed]

23. Zou, L.; Feng, Y.; Xu, G.; Jian, W.; Chao, W. Splenic RNA and MicroRNA Mimics Promote Complement Factor B Production and Alternative Pathway Activation via Innate Immune Signaling. J. Immunol. 2016, 196, 2788-2798. [CrossRef]

24. Jiang, Q.; Wu, C.; Zhang, Q. microRNA-34a participates in lipopolysaccharide mediated sepsis related renal function impairment via Kruppel-like factor 4. Zhonghua Wei Zhong Bing Ji Jiu Yi Xue 2018, 30, 351-354. [PubMed]

25. Tod, P.; Róka, B.; Kaucsár, T.; Szatmári, K.; Vizovišek, M.; Vidmar, R.; Fonovič, M.; Szénási, G.; Hamar, P. Time-Dependent miRNA Profile during Septic Acute Kidney Injury in Mice. Int. J. Mol. Sci. 2020, 21, 5316. [CrossRef] [PubMed]

26. Xu, J.; Feng, Y.; Jeyaram, A.; Jay, S.M.; Zou, L.; Chao, W. Circulating Plasma Extracellular Vesicles from Septic Mice Induce Inflammation via MicroRNA- and TLR7-Dependent Mechanisms. J. Immunol. 2018, 201, 3392-3400. [CrossRef] [PubMed]

27. Zhang, J.; Fun, S.L.; Liu, Y.; Liu, Y.L.; Wang, W.J. Analysis of MicroRNA Expression Profiles in Weaned Pig Skeletal Muscle after Lipopolysaccharide Challenge. Int. J. Mol. Sci. 2015, 16, 22438-22455. [CrossRef] [PubMed]

28. Wang, J.F.; Yu, M.L.; Yu, G.; Bian, J.J.; Deng, X.M.; Wan, X.J.; Zhu, K.M. Serum miR-146a and miR223 as potencial new biomarkers for sepsis. Biochem. Biophys. Res. Commun. 2010, 394, 184-188. [CrossRef]

29. Wang, L.; Wang, H.C.; Chen, C.; Zeng, J.; Wang, Q.; Zheng, L.; Yu, H.D. Differential expression of plasma miR-146a in sepsis patients compared with non-sepsis-SIRS patients. Exp. Ther. Med. 2013, 5, 1101-1104. [CrossRef] [PubMed]

30. Puskarich, M.A.; Nandi, U.; Shapiro, N.I.; Trzeciak, S.; Kline, J.A.; Jones, A.E. Detection of microRNAs in patients with sepsis. J. Acute Dis. 2015, 4, 101-106. [CrossRef]

31. Liu, J.; Shi, K.; Chen, M.; Xu, L.; Hong, J.; Hu, B.; Yang, X.; Sun, R. Elevated miR-155 expression induces immunosuppression via CD39+regulatory T-cells in sepsis patient. Int. J. Infect. Dis. 2015, 40, 135-141. [CrossRef] [PubMed]

32. Povoa, P.; Coelho, L.; Almeida, E.; Fernandes, A.; Mealha, R.; Moreira, P.; Sabino, H. C-reactive protein as a marker of infection in critically ill patients. Clin. Microbiol. Infect. 2005, 11, 101-108. [CrossRef] [PubMed]

33. Barati, M.; Alinejad, F.; Bahar, M.A.; Tabrisi, M.S.; Shamshiri, A.R.; Bodouhi, N.O.; Karimi, H. Comparison of WBC, ESR, CRP and PCT serum levels in septic and non-septic burn cases. Burns 2008, 34, 770-774. [CrossRef] [PubMed]

34. Kopterides, P.; Siempos, I.I.; Tsangaris, I.; Tsantes, A.; Armaganidi, A. Procalcitonin-guided algorithms of antibiotic therapy in the intensive care unit: A systematic review and meta-analysis of randomized controlled trials. Crit. Care. Med. 2010, 38, $2229-2241$. [CrossRef]

35. Jawa, R.S.; Anillo, S.; Huntoon, K.; Baumann, H.; Kulaylat, M. Interleukin-6 in surgery, trauma, and critical care part II: Clinical implications. J. Intensive Care. Med. 2011, 26, 73-87. [CrossRef] [PubMed]

36. Samraj, R.S.; Zingarelli, B.; Wong, H.R. Role of biomarkers in sepsis care. Shock 2013, 40, 358-365. [CrossRef] [PubMed]

37. O'Connell, R.M.; Rao, D.S.; Baltimore, D. MicroRNA regulation of inflammatory responses. Annu. Rev. Immunol. 2012, 30, 295-312. [CrossRef] [PubMed]

38. Wang, Z.H.; Liang, Y.B.; Tang, H.; Chen, Z.B.; Li, Z.Y.; Hu, X.C.; Ma, Z.F. Dexamethasone down-regulates the expression of microRNA-155 in the livers of septic mice. PLoS ONE 2013, 8, e80547. [CrossRef]

39. El Gazzar, M.; Church, A.; Liu, T.; McCall, C.E. MicroRNA-146a regulates both transcription silencing and translation disruption of TNF- $\alpha$ during TLoR4-induced gene reprogramming. J. Leukoc. Biol. 2011, 90, 509-519. [CrossRef] [PubMed]

40. Sonkoly, E.; Pivarcsi, A. Advances in microRNAs: Implications for immunity and inflammatory diseases. J. Cell. Mol. Med. 2009, 13, 24-38. [CrossRef]

41. Sheng, B.; Zhao, L.; Zang, X.; Zhen, J.; Chen, W. miR-375 ameliorates sepsis by downregulating miR-21 level via inhibiting JAK2-STAT3 signaling. Biomed. Pharmacother. 2017, 86, 254-261. [CrossRef] [PubMed]

42. Yao, L.; Liu, Z.; Zhu, J.; Liver, B.; Chai, C.; Tian, Y. Clinical evaluation of circulating microRNA-25 level change in sepsis and its potential relationship with oxidative stress. Int. J. Clin. Exp. Pathol. 2015, 8, 7675-7684. [PubMed] 
43. Orangi, E.; Motovali-Bashi, M. Evaluation of miRNA-9 and miRNA-34a as potential biomarkers for diagnosis of breast cancer in Iranian women. Gene 2019, 687, 272-279. [CrossRef] [PubMed]

44. Tacke, F.; Roderburg, C.; Benz, F.; Cardenas, D.V.; Luedde, M.; Hippe, H.J.; Frey, N.; Vucur, M.; Gautheron, J.; Koch, A. Levels of circulating miR-133a are elevated in sepsis and predict mortality in critically ill patients. Crit. Care Med. 2014, 42, 1096-1104. [CrossRef] [PubMed]

45. Sun, Y.; Jin, X.L.; Zhang, T.T.; Jia, C.W.; Chen, J. MiR-150-5p inhibits the proliferation and promoted apptosis of pancreatic cancer cells. Zhonghua Bing Li Xue Za Zhi 2013, 42, 460-464. [PubMed]

46. Lu, J.; Guo, S.; Ebert, B.L.; Zhang, H.; Peng, X.; Bosco, J.; Pretz, J.; Schlanger, R.; Wang, J.Y.; Mak, R.H.; et al. MicroRNA-mediated control of cell fate in megakaryocyte-erythrocyte progenitors. Dev. Cell. 2008, 14, 843-853. [CrossRef]

47. Vasilescu, C.; Rossi, S.; Shimizu, M.; Tudor, S.; Veronese, A.; Ferracin, M.; Nicoloso, M.S.; Barbarotto, E.; Popa, M.; Stanciulea, O.; et al. MicroRNA fingerprints identify miR-150 as a plasma prognostic marker in patients with sepsis. PLoS ONE 2009, 4, e7405. [CrossRef]

48. Ma, Y.; Vilanova, D.; Atalar, K.; Delfour, O.; Edgeworth, J.; Ostermann, M. Genome-wide sequencing of cellular microRNAs identifies a combinatorial expression signature diagnostic of sepsis. PLoS ONE 2013, 8, e75918. [CrossRef] [PubMed]

49. Roderburg, C.; Luedde, M.; Vargas Cardenas, D.; Vucu, M.; Scholten, D.; Frey, N.; Koch, A.; Trautwein, C.; Tacke, F.; Luedde, T. Circulating microRNA-150 serum levels predict survival in patients with critical illness and sepsis. PLoS ONE 2013, 8, e54612. [CrossRef]

50. How, C.K.; Hou, S.; Shih, H.C.; Huang, M.S.; Chiou, S.H.; Lee, C.H.; Juan, C.C. Expression profile of MicroRNAs in gram-negative bacterial sepsis. Shock 2015, 43, 121-127. [CrossRef]

51. Neilsen, P.M.; Noll, J.E.; Mattiske, S.; Bracken, C.P.; Gregory, P.A.; Schulz, R.B.; Lim, S.P.; Kumar, R.; Suetani, R.J.; Goodall, G.J.; et al. Mutant p53 drives invasion in breast tumors tHiRough up-regulation of miR-155. Oncogene 2013, 32, 2992-3000. [CrossRef] [PubMed]

52. Navon, R.; Wang, H.; Steinfeld, I.; Tsalenko, A.; Ben-Dor, A.; Yakhini, Z. Novel rank-based statistical methods reveal microRNAs with differential expression in multiple cancer types. PLoS ONE 2009, 4, e8003. [CrossRef] [PubMed]

53. Wang, H.; Zhang, P.; Chen, W.; Feng, D.; Jia, Y.; Xie, L. Serum microRNA signatures identified by Solexa sequencing predict sepsis patients' mortality: A prospective observational study. PLoS ONE 2012, 7, e38885. [CrossRef] [PubMed]

54. Camps, C.; Saini, H.K.; Mole, D.R.; Choudhry, H.; Reczko, M.; Guerra-Assunção, J.A.; Tian, Y.-M.; Buffa, F.M.; Harris, A.L.; Hatzigeorgiou, A.G.; et al. Integrated analysis of microRNA and mRNA expression and association with HIF binding reveals the complexity of microRNA expression regulation under hypoxia. Mol. Cancer 2014, 13, 28. [CrossRef] [PubMed] 